\title{
Who Needs Facebook Anyway - Privacy and Sociality in Social Network Sites
}

\author{
Ronald E. Leenes \\ Tilburg Institute for Law, Technology, and Society, The Netherlands \\ R.E.Leenes@uvt.nl
}

\begin{abstract}
SNSs pose a plethora of privacy issues that are reasonably well known and understood. Many issues boil down to the same problem: information makes it to the wrong audience. This problem is inherent to the design and business model of the current social network sites. How to cope with this? Two approaches seem obvious: address user behaviour and/or address the architecture of social network sites. In this presentation I will argue that the options for changing users' behaviour are limited by highlighting some of the social dynamics of SNS. Next I will focus on three areas of privacy issues: those caused by individual SNS users, those used by the SNS platform providers and those caused by the non subscribers. I will show how these issues are addressed within the EU FP7 project PrimeLife in the Clique prototype.
\end{abstract}

Short Biography. Dr. Ronald Leenes is full professor in regulation by technology at TILT, the Tilburg Institute for Law, Technology, and Society (Tilburg University). His primary research interests are privacy and identity management, ID fraud, biometrics and Online Dispute Resolution.

Leenes (1964) studied Public Administration and Public Policy at the University of Twente. He received his $\mathrm{PhD}$ for a study on hard cases in law and Artificial Intelligence and Law from the same university.

Ronald was work package leader on socio-cultural aspects of privacy-enhancing IDM in the EU FP6 PRIME project. He was work package leader for access control in social software in the FP7 PrimeLife project and is work package on legal requirements within the FP7 ENDORSE project. He has contributed to and edited various deliverables for the EU FP6 Network of Excellence 'Future of IDentity in the Information Society' (FIDIS). He has published extensively on privacy in online applications, including Second Life and Social Network Sites. 